\title{
Parceria e Empowerment A Experiência da Iniciativa EQUAL
}

Maria do Carmo Nunes *

\begin{abstract}
$\mathrm{R}$ trabalhar em parceria e empowerment. Admite-se que é na convergência destes dois requisitos que residirá importante valor acrescentado do Programa EQUAL, em particular o seu contributo para uma maior participação e responsabilização da sociedade civil na execução das políticas sociais e para melhorar as respostas e a eficácia das intervenções de combate às desigualdades e à exclusão social e da adaptação das organizações a uma nova economia.

Procede-se a uma primeira reflexão sobre os desafios que se colocam às "parcerias de desenvolvimento" e identificam-se factores críticos a monitorizar ao longo dos dois anos de execução dos projectos.
\end{abstract}

Palavras-Chave: parceria de desenvolvimento; empowerment; públicos desfavorecidos

\section{O EQUAL: um programa estratégico e de cidadania}

O EQUAL é um programa de Iniciativa Comunitária financiado pelo FSE no período 2000-2006, que apresenta características distintas dos programas do Quadro Comunitário de Apoio, com destaque para a inovação e a experimentação, a transnacionalidade e a disseminação de práticas bem sucedidas. São estes requisitos que têm permitido atribuir às Iniciativas Comunitárias, e no caso presente ao Programa EQUAL, um papel importante na estruturação do sistema de formação e emprego, na melhoria dos instrumentos de apoio ao desenvolvimento dos recursos humanos, na capacitação das organizações e profissionais envolvidos (formadores e outros agentes) e na eficácia dos processos de integração no mercado de trabalho.

Neste sentido, o Programa EQUAL é um programa estratégico.

Mas, para além dos requisitos referidos, já presentes nas Iniciativas Emprego e ADAPT suas antecessoras, os projectos financiados pela Iniciativa EQUAL apresentam mais duas características específicas: devem ser obrigatoriamente desenvolvidos em parceria e pôr em prática o empowerment.
Estas duas exigências, impostas pela Comissão Europeia na sua Comunicação aos Estados-mem$\operatorname{bros}^{1}$, foram incorporadas no Programa EQUAL português $^{2}$ e no Guia do Utilizador ${ }^{3}$ com a consciência de que o país, e em particular as organizações que viessem a desenvolver em parceria projectos no âmbito desta iniciativa, tinham pela frente um novo desafio à cultura e às práticas nacionais, mas também tinham uma nova oportunidade para se posicionarem diferentemente no "mercado" em que actuam e para retirar dividendos das alianças e parcerias que viessem a estabelecer.

Estes dois novos requisitos da Iniciativa EQUAL permitem considerá-la, simultaneamente, como bastante mais exigente e com maior potencial de mudança que as suas antecessoras Emprego e ADAPT.

É nossa convicção de partida que é na convergência das práticas de parceria e de $\mathrm{em}$ powerment que residirá o maior valor acrescentado do EQUAL. E que é neste "cruzamento", nesta conjugação de vontades e de competências distintas, que será possível garantir a continuidade e a auto-sustentação das intervenções para além da vida útil dos projectos (pós-financiamento público), o que constitui uma finalidade importante do EQUAL face a 2006 e à perspectiva de redução dos apoios comunitários.

\footnotetext{
Economista. Chefe de Projecto no Gabinete de Gestão do Programa EQUAL.Contacto:Av. da República, 62 - $7^{\circ}$; Telefone: 217994930

Comissão Europeia (2002), Directrizes para a iniciativa comunitária EQUAL, (2000/C 127/02), Jornal Oficial das Comunidades Europeias, 5 Maio.

${ }^{2}$ Gabinete de Gestão EQUAL (2002), Programa Operacional EQUAL - Portugal, Ministério do Trabalho e da Solidariedade.

${ }^{3}$ Gabinete de Gestão EQUAL (2001), Guia de Apoio ao Utilizador EQUAL, Ministério do Trabalho e da Solidariedade.
} 
Está aqui em causa saber em que medida uma maior participação e responsabilização da sociedade civil na execução das políticas sociais, e em particular através de parcerias e alianças público-privadas, contribui para melhorar as respostas e a eficiência das intervenções de combate às desigualdades e à exclusão social e de adaptação das organizações a uma nova economia.

A resposta final a esta questão só nos será dada, porventura, no final da execução do programa. Mas para garantir o sucesso e a mudança que propõe, é importante que se reflicta sobre os aspectos que se vêm já revelando críticos na actual fase de montagem das parcerias e dos projectos (entre Novembro de 2001 e Maio de 2002, os projectos procedem ao aprofundamento do diagnóstico de necessidades, ao planeamento das acções, ao alargamento e consolidação da parceria e só a partir desta data, e durante dois anos, se executa o projecto propriamente $\left.\operatorname{dito}^{4}\right)$; que se reflicta sobre os desafios a que as parcerias e os parceiros devem responder para alcançar os objectivos a que se propuseram, e sobre os elementos que devem constar de um processo de monitorização, que venha a ser um verdadeiro processo de aprendizagem, capaz de potenciar resultados sustentáveis e socialmente válidos.

\section{As Parcerias de Desenvolvimento}

As parcerias EQUAL, designadas por Parcerias de Desenvolvimento (P.D.) devem reunir "entidades interessadas, com competências adequadas, que cooperam para responder através de uma abordagem integrada a problemas pluridimensionais" (Comissão Europeia, 2002).

Este requisito tem subjacente a ideia que a estratégia europeia para o emprego para ser eficaz deve traduzir-se em acções, quer no plano territorial quer sectorial, susceptíveis de gerar uma nova cooperação, no quadro da uma estratégia integrada de luta contra as discriminações e a exclusão social.

Tem também subjacente a ideia que uma resposta integrada a problemas pluridimensionais, só é possível com a cooperação e participação activa de organizações de perfil distinto e de competências complementares, que criem "pontes" entre prestações e serviços hoje desligados uns dos outros, convergindo para a resolução de um problema que nenhum, só por si, seria capaz de resolver. As parcerias, um pouco por todo o lado, multiplicam-se. "O mundo tornou-se demasiado complexo e interdependente para uma só instituição ou sector responder eficazmente aos desafios e oportunidades de hoje" (Zadek; Hojenseard; Raynard, 2000).

As P.D. envolvem entidades relevantes para a problemática que cada projecto trata (organismos públicos, organizações sem fins lucrativos, parceiros sociais, empresas, etc.), aproximando-se daquilo que The Copenhagen Centre designa por "novas parcerias sociais" - "pessoas e organizações dos sectores público, privado e civil, que se comprometem voluntariamente em relações inovadoras e mutuamente benéficas, dirigidas a fins sociais comuns, através da combinação de recursos e competências".

Entre nós, não é frequente a participação das empresas em parcerias de cariz social. Por isso o Programa EQUAL português deu especial ênfase ao envolvimento das empresas nas parcerias, incluindo-o e valorizando-o como critério de avaliação das candidaturas.

Considerou-se que a participação das empresas nas parcerias de desenvolvimento não só como destinatárias dos projectos (na acepção de beneficiárias), mas também como pares, era fundamental para dar consistência e realismo à formação e à orientação profissional dos mais desfavorecidos e, no limite, assegurar a sua inclusão.

É importante que as empresas, o "sector social" e a própria administração pública trabalhem mais em conjunto, explorem interesses comuns e aprendam uns com os outros, e que as empresas comecem a incluir nos seus objectivos empresariais e de negócio as actividades sociais que desenvolvem, assumindo que estas actividades têm também um retorno económico.

Numa parceria todos os parceiros têm de dar e têm de ganhar. É, assim, natural que as empresas se posicionem na parceria numa lógica de negócio. A pouca expressão que, em Portugal, ainda têm as actividades que habitualmente se enquadram na "responsabilidade social das organizações" (e de

\footnotetext{
${ }^{4}$ Os projectos EQUAL desenvolvem-se em três etapas: a Acção 1, que é a etapa de montagem da parceria, do diagnóstico de necessidades e da concepção e planeamento do projecto (decorre entre Novembro e Maio 2002); a Acção 2 que constitui a etapa de desenvolvimento e avaliação do projecto propriamente dito (com a duração máxima de 2 anos), e a Acção 3 em que se promove a disseminação dos produtos e práticas bem sucedidas.
} 
que é um excelente exemplo a ausência de candidaturas na área de intervenção da EQUAL “cidadania empresarial - economia cívica”) poderá dever-se em grande parte ao facto deste tipo de actividades ser encarado como um custo sem retorno.

Em muitos países, e os Estados Unidos são um bom exemplo, está em crescimento a participação de empresas em parcerias público-privadas para encorajar a contratação de grupos "problema", como o das pessoas com deficiência. Para esta participação as empresas apontam razões como a necessidade de diversificar recursos, de aumentar o pool de competências disponíveis, de melhorar a sua imagem e reputação no mercado, etc., para além de ser "o que é certo fazer". "Trabalhar com a task force (para o emprego de adultos com deficiência) foi uma oportunidade de não só fazer coisas boas, mas também de acrescer valor ao nosso negócio (...). Entrar nesta parceria foi uma decisão empresarial (...); queremos apoiar as pessoas a ajudar-se a si próprias, mas queremos também ser bem sucedidos" (vice-presidente da empresa Monster.com, citado por Whiting, 2001).

E os exemplos poderiam multiplicar-se. Com efeito, a responsabilidade social das empresas vem assumindo uma importância crescente e os futuros gestores encaram-na como uma alta prioridade: "de acordo com um estudo efectuado por Students for Responsible Business, dirigido a 2.100 alunos MBAs, de 50 cursos de licenciatura em gestão, $79 \%$ destes alunos pensam que a empresa tem de tomar em consideração o seu impacto na sociedade em termos de ambiente, igualdade de oportunidades, relações trabalho-família e de envolvimento da comunidade; $50 \%$ responderam que aceitariam um salário inferior para trabalhar numa empresa "muito responsável socialmente" e $43 \%$ afirmaram que não trabalhariam numa empresa que não fosse socialmente responsável" (Barrett,1998).

Inúmeros relatos de experiências de parceria de empresas com o "sector social" revelam que aquelas têm muito a aprender com a "economia social": aprender a trabalhar para uma missão (e não só pelo lucro), a ser melhores empregadores, a estar mais atentas aos interesses dos seus colaboradores, clientes e comunidades locais, etc. Em contrapartida, as organizações da economia social podem aprender com as empresas a ser competitivas, a orientar-se mais pelos resultados, a ser mais empreendedoras, etc. (Sagawa e Segal, 2000).
Por outro lado, as organizações sem fins lucrativos, entre nós tão dependentes ainda da subsidiação pública (que é em si precária e descontínua), têm de caminhar mais no sentido da sua auto-sustentação, quer gerando rendimentos próprios quer através do recurso a uma contratualização pública consistente e contínua que incentive um "terceiro sector" forte, independente e realizador. Também neste aspecto o Programa EQUAL português foi exigente ao valorizar as parcerias que dessem garantias de viabilidade para além da vida útil dos projectos (Gabinete de Gestão EQUAL, 2001).

A diversidade de parceiros e de oportunidades que uma parceria propõe, mostra bem que esta não é só uma nova estrutura "promotora" de projectos. É uma nova cultura e uma nova filosofia de trabalho, de abertura e de cooperação. É, também, um mecanismo capaz de permitir resultados superiores aos que conseguiriam o somatório linear dos recursos e competências dos parceiros envolvidos. É este valor acrescentado, esta "emergência", este "poder de mais de um" que se espera de uma parceria EQUAL.

\section{O Empowerment}

O empowerment é entendido na EQUAL como a "participação activa e a responsabilização das pessoas, comunidades e organizações, no sentido da apropriação sustentada dos processos de mudança em que estão envolvidas, e com base na gestão das suas próprias necessidades, recursos e aptidões" (Gabinete de Gestão EQUAL,2001).

Este conceito de empowerment aplica-se quer às parcerias de desenvolvimento e às organizações nelas envolvidas quer aos próprios destinatários. Em qualquer dos casos, a estratégia do empowerment radica na constatação de que é indispensável aumentar o grau de participação e responsabilização observados na sociedade e, em particular, naqueles que são vítimas de discriminações, e que dispõem de poucas possibilidades de participar e influenciar as acções que de alguma forma lhes dizem respeito. Neste sentido, o empowerment assume-se como um princípio da cidadania activa e como um processo capaz de aproximar e melhor adaptar as intervenções às necessidades e expectativas dos grupos-alvo.

A operacionalização do empowerment a nível das parcerias implica que todos os parceiros de uma parceria assumam responsável e participadamente 


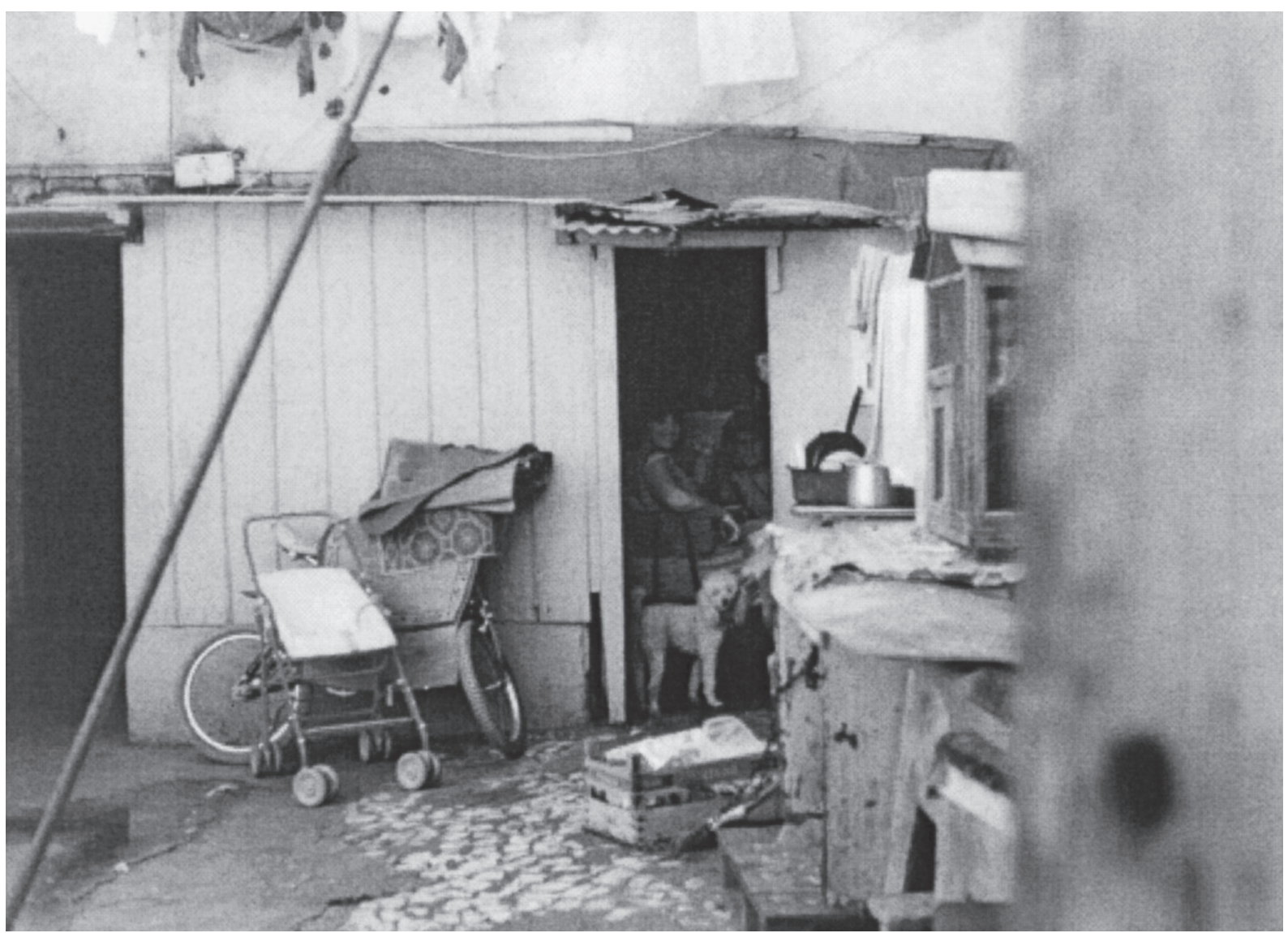

Foto de Alexandra Castro

o seu papel no desenvolvimento do projecto e no processo de decisão interno à P.D.. Implica, também, que todos os parceiros promovam o envolvimento dos seus colaboradores no projecto, na sua concepção, desenvolvimento e avaliação, e invistam numa mudança de atitudes, no sentido de uma maior responsabilização e autonomia e numa nova cultura organizacional, de abertura à participação e ao diálogo.

As parcerias surgem, assim, como uma oportunidade para as organizações implicadas reverem os próprios modelos de organização e gestão interna (processos de comunicação e de tomada de decisão, organização do trabalho, etc.) e de relacionamento com a envolvente externa (mobilização, envolvimento e implicação de actores locais, etc.).

Neste contexto, o empowerment pode ser perspectivado como um processo de democratização dos processos de decisão nas organizações e de reforço do papel e contributo da sociedade civil na resolução dos problemas dos mais desfavorecidos. Sociedade civil em sentido amplo, onde se incluem as organizações que actuam junto dos grupos mais desfavorecidos e que não raro carecem de reforçar a sua representatividade e "legitimidade", deixando "espaço" a movimentos de auto-representação e auto-determinação das pessoas em situação de desvantagem ou mesmo de exclusão (self advocacy).

É neste âmbito que as Parcerias de Desenvolvimento se podem revelar como um espaço de participação responsável e a EQUAL como um programa catalisador e indutor de mudanças no funcionamento do sistema social, de emprego e de formação, como um programa para a cidadania.

\section{Montar as Parcerias e Aplicar o Empowerment: um primeiro balanço}

Como se referiu, a EQUAL está em plena fase de montagem das parcerias e de concepção dos projectos até Maio de 2002. É, assim, cedo para quaisquer conclusões. Todavia, a partir das candidaturas apresentadas à Acção 1 e do acompanhamento entretanto feito no terreno, é possível, desde já, efectuar uma primeira leitura e reflexão sobre 
algumas características e aspectos críticos das parcerias "fundadoras".

\section{As Parcerias e o Perfil dos Parceiros}

Nos 116 projectos seleccionados para a Acção 1, estão envolvidas cerca de 460 entidades, o que significa que cada parceria "fundadora" é composta em média por 4 parceiros. É previsível que este número venha a aumentar substancialmente no final desta etapa, e que a tipologia de parceiros sofra também alterações, em consequência das orientações da gestão do programa para uma maior inclusão de empresas nas parcerias e também de organizações sindicais, menos presentes do que as organizações patronais nas parcerias "fundadoras".

No quadro junto compara-se o tipo de parceiros presentes nas parcerias do pilar da "empregabilidade" (pilar orientado para uma intervenção directa junto de públicos desfavorecidos) com o da "adaptabilidade" (pilar mais orientado para a qualificação, adaptação ou reconversão das organizações e dos seus trabalhadores), já que se trata de duas "prioridades"5 com objectivos e conteúdos bastante distintos, implicando parcerias também elas distintas.
A primeira diferença reside no número médio de parceiros - 4,5 na "empregabilidade" e 3,6 na "adaptabilidade" - a evidenciar, talvez, uma maior necessidade sentida pelas parcerias da "empregabilidade" de que é indispensável conjugar competências distintas e complementares para dar resposta aos problemas complexos e plurifacetados dos grupos desfavorecidos, facto que constitui aspecto central deste pilar.

Neste pilar observa-se uma presença forte de organizações sem fins lucrativos (IPSS, ONG's, Associações de Desenvolvimento Local, Fundações, Cooperativas, etc.), o que era expectável face à sua vocação específica, e também de organismos públicos, em particular de autarquias, merecendo ser realçada esta "aproximação ao terreno" (ao "local" e aos "grupos-alvo") que se verifica neste pilar. É de salientar o número já muito positivo de empresas envolvidas, assumindo simultaneamente um papel de "par" (ex. disponibilização de oportunidades de estágio ao público-alvo) e de beneficiárias (ex.. formar pessoas na óptica de poder vir a dispor de mão de obra qualificada no futuro; alargamento do seu mercado, etc.).

$\mathrm{Na}$ "adaptabilidade" predominam as entidades formadoras (centros de formação protocolar e

Quadro 1 - Tipologia de parceiros nos pilares "Empregabilidade" e "Adaptabilidade"

\begin{tabular}{|c|c|c|c|c|}
\hline \multirow{2}{*}{ Tipologia de parceiros } & \multicolumn{2}{|c|}{ Empregabilidade } & \multicolumn{2}{|c|}{ Adaptabilidade } \\
\hline & $\begin{array}{c}\mathrm{N}^{\mathrm{o}} \\
\text { parceiros }\end{array}$ & $\%$ & $\begin{array}{c}\mathrm{N} .^{\mathrm{o}} \\
\text { parceiros }\end{array}$ & $\%$ \\
\hline Organismos públicos & 60 & 34,9 & 23 & 19,3 \\
\hline Entidades Formadoras & 16 & 9,3 & 30 & 25,2 \\
\hline Organizações sem fins lucrativos & 61 & 35,5 & 11 & 9,2 \\
\hline Empresas & 16 & 9,3 & 14 & 11,8 \\
\hline Empresas consultoras & 4 & 2,3 & 14 & 11,8 \\
\hline Organizações patronais e sindicais & 10 & 5,8 & 23 & 19,3 \\
\hline Outros & 5 & 2,9 & 4 & 3,4 \\
\hline TOTAL & 172 & 100,0 & 119 & 100,0 \\
\hline N. ${ }^{\circ}$ médio parceiros por P.D. & 4,5 & - & 3,6 & - \\
\hline N. ${ }^{o}$ de Parcerias de Desenvolvimento & 38 & - & 33 & - \\
\hline
\end{tabular}

Fonte: Gabinete de Gestão do Programa EQUAL

A Iniciativa EQUAL é composta por cinco grandes pilares ou domínios temáticos: empregabilidade, espírito empresarial, adaptabilidade, igualdade de oportunidades para as mulheres e os homens e requerentes de asilo. 
também centros tecnológicos, em que a formação surge muito associada à inovação tecnológica), logo seguidas pelos organismos públicos e pelas organizações patronais e sindicais (sobretudo patronais) e, depois, pelas empresas, aqui enquanto beneficiárias.

Apesar da forte recomendação à integração nas parcerias de desenvolvimento de organizações sindicais, é possível que o seu número fique aquém do desejável. Esta orientação do Programa EQUAL, que teve por base o requisito do "empowerment" $\mathrm{e}$ a reconhecida necessidade de incentivar o diálogo social, apesar de acolhida de forma diferente pelas parcerias fundadoras, constitui um enorme salto qualitativo relativamente a outros programas com financiamento público.

Em síntese, temos:

$\mathrm{Na}$ "empregabilidade": parcerias maiores, com organizações próximas do grupo-alvo e do "local", e já com algumas empresas (ainda poucas) visualizando "retorno" para as suas intervenções sociais.

$\mathrm{Na}$ "adaptabilidade": parcerias mais pequenas, onde predominam centros de formação, nomeadamente associando a formação à inovação tecnológica, parceiros sociais e empresas, aqui mais como "beneficiárias" do que como "pares".

\section{A Aplicação do Empowerment}

O Programa EQUAL português incentivou fortemente as parcerias a mobilizar e envolver os actores-chave locais na concepção do projecto e a fazer também participar os públicos-alvo, como forma de melhor adequar os projectos às suas expectativas e às necessidades locais. Por outro lado, estimulou as parcerias a envolver os trabalhadores das entidades parceiras e das próprias empresas implicadas nos projectos, na linha de estimulo ao diálogo so-

Quadro 2 - Notação média dos projectos aprovados na Acção 1, nos critérios "inovação" e "empowerment" (escala de 1 a 100), por áreas de intervenção)

\begin{tabular}{|c|c|c|c|}
\hline Áreas de Intervenção & Inovação & $\begin{array}{c}\text { Empowerment } \\
\text { de } \\
\text { actores-chave e de } \\
\text { destinatários finais }\end{array}$ & $\begin{array}{c}\text { Empowerment } \\
\text { dos trabalhadores das } \\
\text { organizações implicadas } \\
\text { na parceria }\end{array}$ \\
\hline $\begin{array}{l}\text { Percursos integrados de orientação-formação- } \\
\text {-inovação }\end{array}$ & 61,15 & 58,56 & 46,06 \\
\hline Prevenção de discriminações raciais & 53,60 & 41,50 & 28,00 \\
\hline Criação de empresas e desenvolvimento local & 53,26 & 49,81 & 46,67 \\
\hline $\begin{array}{l}\text { Qualificação das organizações da economia } \\
\text { social }\end{array}$ & 74,76 & 61,25 & 50,00 \\
\hline Formação em contexto de trabalho & 71,20 & 57,50 & 64,00 \\
\hline Adaptação e reconversão profissional & 69,00 & 57,08 & 53,33 \\
\hline Modernização e inovação organizacional & 60,77 & 55,00 & 55,33 \\
\hline Sociedade da informação e do conhecimento & 64,22 & 59,44 & 57,78 \\
\hline Conciliação vida familiar-vida profissional & 67,67 & 64,58 & 53,33 \\
\hline Eliminação da discriminação no trabalho & 68,00 & 56,00 & 40,00 \\
\hline Requerentes de asilo & 64,00 & 72,50 & 60,00 \\
\hline Notação Média & 61,38 & 55,80 & 48,97 \\
\hline
\end{tabular}

Fonte: Gabinete de Gestão do Programa EQUAL 
cial e à participação na mudança e desenvolvimento das organizações.

As actividades de empowerment previstas pelas parcerias candidatas à Acção 1 e observadas no acompanhamento dos projectos, permitem afirmar que existe ainda um percurso a efectuar nas práticas de audição, envolvimento e participação de actores-chave e de beneficiários, e que este percurso é ainda mais longo no caso do empowerment dos próprios trabalhadores das organizações envolvidas.

Os projectos aprovados apresentaram, em média, uma notação no requisito "inovação" superior à do empowerment, e a notação do empowerment dos actores-chave e dos destinatários finais foi, em geral, superior à do empowerment dos trabalhadores das organizações envolvidas nos projectos.

O acompanhamento dos projectos no terreno permitiu verificar que as actividades de empowerment assumiram frequentemente o formato de audição de opiniões pela via (passiva) do inquérito (muitas vezes concebidos administrativamente), mais do que uma participação activa dos actores-chave e destinatários, que apelasse a uma dinâmica de grupo e a uma reflexão conjunta, susceptíveis de induzir um maior envolvimento e responsabilização.

Por outro lado, as frágeis práticas de empowerment dos trabalhadores que foram observadas vêm confirmar a urgência em fortalecer uma cultura de participação interna e de diálogo nas organizações, facto que é tanto mais crítico quanto se sabe que a inovação está associada à participação dos colaboradores.

\section{Desafios que se Colocam às Parcerias e aos Parceiros}

A observação da dinâmica das parcerias no terreno permitiu já verificar que trabalhar em parceria vai exigir mudanças nas práticas de cada parceiro e, também, nos valores e cultura próprios de cada um. Trabalhar em parceria é um confronto de ideias e perspectivas, é uma aprendizagem mútua, que requer transparência e abertura, e que obrigará a rever as representações que cada um faz do outro, tantas vezes sustentadas em estereótipos. Vai exigir que se identifiquem e aprofundem interesses comuns, que se delimitem os campos de actuação, e que, ao mesmo tempo que se acrescenta valor aos objectivos e resultados da parceria, se reforcem as competências e os "resultados" de cada parceiro.

Aprender com os outros significa mudar, sem que se altere a vocação própria de cada um.

$\mathrm{O}$ quadro seguinte sistematiza algumas das mudanças que se prevêem necessárias nos valores e práticas de três tipos de parceiros: organismos públicos, organizações sem fins lucrativos que operam no sector social e empresas.

$\mathrm{O}$ acompanhamento dos projectos no terreno permitiu, também, identificar os seguintes factores críticos:

\section{- as pessoas}

A competência e dinamismo das pessoas envolvidas nos projectos e, em particular, a competência e capacidade de liderança dos coordenadores das equipas são os factores mais distintivos das parcerias e dos projectos. São, também, factores críticos do seu sucesso. Por isso mesmo é imperioso suprir a escassez de agentes qualificados que foi observada e que constitui uma ameaça ao sucesso de um programa que aposta na qualidade e na inovação.

Pode-se mesmo afirmar que mais do que a competência e credibilidade das entidades parceiras, são as pessoas que fazem os projectos e marcam a diferença. Outra questão importante é o nível de responsabilidade do coordenador do projecto em cada entidade parceira, já que o seu "estatuto", o seu grau de autonomia, condiciona substancialmente a iniciativa e a dinâmica da própria parceria.

\section{- criar coesão interna e uma cultura comum}

Muitas parcerias carecem de trabalhar em conjunto, em equipa, para que seja efectiva a partilha de valores e de objectivos, para que se clarifique o papel de cada parceiro e se possibilite o entrosamento da sua acção. Só, assim, se cria uma cultura capaz de gerar confiança mútua. A coesão interna, o "alinhamento" com o projecto, o sentido de pertença e a consistência da parceria criam-se partilhando objectivos, identificando e assumindo o contributo de cada um para o projecto e também os ganhos que a participação no projecto traz para cada organização parceira. 
- cooperar para um abordagem integrada e sistémica dos problemas

Fazer com que a parceria não seja um simples somatório linear dos "projectos" de cada parceiro constitui um sério desafio para muitas parcerias de desenvolvimento. Quando a Iniciativa EQUAL propôs que os projectos fossem desenvolvidos por parcerias, agregando parceiros com competências distintas e complementares, fez o enfoque na resolução de problemas que são pluridisciplinares e não na resolução de aspectos parcelares e segmentados do problema. Ou seja, propôs uma abordagem mais sistémica da inclusão social.

É crítico para o sucesso dos projectos que as parcerias de desenvolvimento encarem as "respostas" a dar aos grupos-alvo de forma mais abrangente (combater a exclusão social não é só combater o

Quadro 3 - Mudanças necessárias nos valores e práticas dos parceiros

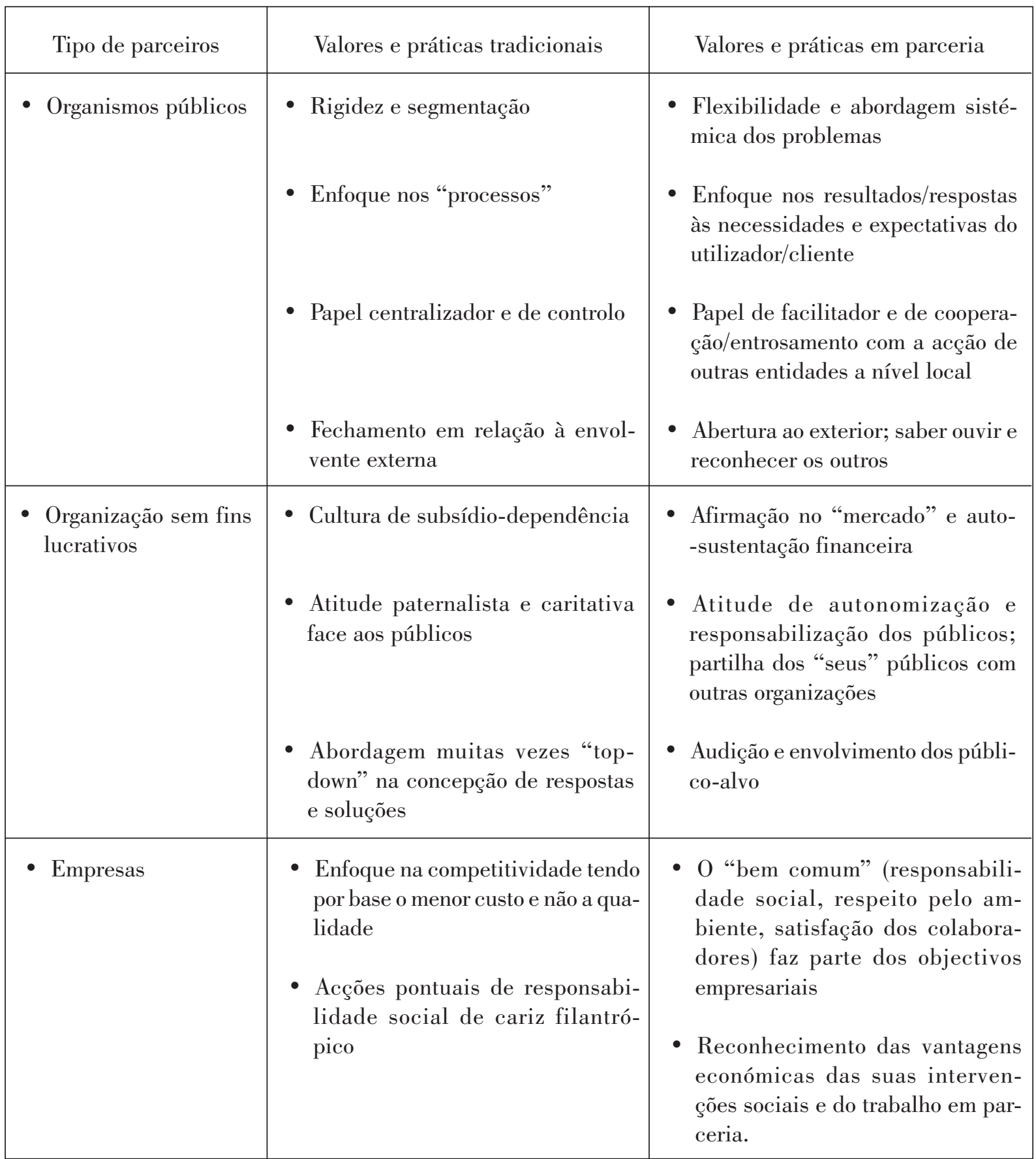


desemprego) e as assumam numa óptica de médio-longo prazo e não apenas de curto prazo.

\section{- o empowerment dos parceiros}

Cada parceiro tem de assumir o seu papel na parceria e o contributo que vai dar ao projecto. É crítico que cada parceiro não deixe nas mãos da "entidade interlocutora" (só porque é ela quem dialoga com a Gestão do Programa) a responsabilidade que lhe cabe na parceria, e que participe de "corpo inteiro" no processo de tomada de decisão. Por outro lado é indispensável que os mecanismos de gestão e funcionamento internos sejam transparentes e participados.

Os aspectos críticos referidos retractam apenas alguns dos desafios com que as parcerias de desenvolvimento se confrontam. Ganhar estes desafios e aproveitar o potencial de mudança das parcerias obrigará a uma monitorização do seu trabalho no terreno e ao retorno permanente dos resultados aos interessados.

Entre os elementos-chave a monitorizar nas parcerias de desenvolvimento contam-se:

\section{Referências Bibliográficas}

ADAPTNEWS (2000), The Newsletter of the ADAPT Initiative, Winter.

ANDERSON, P. (1999), Give and take, Marketing Week, Aug 26, London.

BARRETT, R. (1998), Liberating the corporate soul-building a visionary organization, Butterworth Heinemann.

COMISSÃO EUROPEIA (2002), Directrizes para a iniciativa comunitária EQUAL, (2000/C 127/02), Jornal Oficial das Comunidades Europeias, 5 Maio.

GABINETE DE GESTÃO EQUAL (2001), Guia de Apoio ao Utilizador EQUAL, Ministério do Trabalho e da Solidariedade.

GABINETE DE GESTÃo EQUAL (2002), Programa Operacional EQUAL - Portugal, Ministério do Trabalho e da Solidariedade.
- clareza dos objectivos centrais da P.D. e do papel de cada parceiro;

- grau de interacção dos diferentes parceiros;

- eficácia, transparência e "partilha" do sistema de gestão, organização e comunicação interna da P.D.;

- capacidade de liderança;

- empowerment de parceiros e de colaboradores;

- competências das pessoas;

- enfoque nos resultados e nos utilizadores.

Do acompanhamento e da reflexão que vierem a ser feitos quer pela gestão do programa quer pelas próprias parcerias, numa interacção estreita e permanente, poderá resultar o salto qualitativo que todos esperamos para as organizações e para as pessoas envolvidas, para a melhoria das intervenções e sua sustentação futura, e para a satisfação das necessidades dos destinatários finais.

GOOGINS, B.K.; ROCHILIN, S.A. (2000), Creating the partnership society: understanding the rhetoric and reality of cross-sectoral partnership, Business and Society Review, 105:1 127-144.

GRIBBEN, C.; PINNINGTON, K.; WILSON,A. (2001), Government as Partners, The Copenhagen Centre.

KJAER, L.; RAYNARD, P. (2002), Local Partnerships in Europe, The Copenhagen Centre.

SAGAWA. S.; SEGAL, E. (2000), Common interest common good: Creating value through business and social sector partnership, California Management Review, Berkley.

WHITING, M.A. (2001), Hiring workers with disabilities, Across the Board, Nov/Dec, New York.

ZADEK,S.; HOJENSEARD,N.; RAYNARD,P. (2000), The New Economy of Corporate Citizenship, The Copenhagen Centre. 